\title{
APOCALYPTICAL AND UTOPIAN MOTIVATION FOR CHANGE IN SOCIETY
}

\author{
Tor SANDVIK \\ Oslomet - Oslo Metropolitan University, Norway
}

\begin{abstract}
Actions executed in the name of sustainable development by corporations capable of changing society in a fundamental way often have similar goals, but sometimes conflicting motivations. This is often reflected in the language they use to justify change. The sometimes apocalyptic motivation for change stems from sources capable of changing society's mindset, such as contemporary media. Some organisations working on fundamental societal change, such as the United Nations, will express their justifications using language supportive of a utopian goal. An action that is taken with the motive of creating a utopia can look quite different from an action that is executed to avoid an apocalypse. There seems to be a need for reflection in design education on big change and motivation, as this paper will discuss. Therefore, the research question is: Can design thinking be used to create motivation for sustainable development to aid global actors reach their expected or improved outcomes? Although this paper has a traditional structure, it's goal is to promote discussion rather than promoting new insight and answers in this specific field. The findings are derived from two case studies of the Norwegian climate lawsuit and Equinor's justification for its carbon capture and storage project.
\end{abstract}

Keywords: Climate change, sustainability, utopia, apocalypse, motivation

\section{MOTIVATION}

This paper discusses the motivation behind actions taken in the name of sustainable development. One action performed twice with conflicting motivations might not have similar results. Tear a piece of paper with anger, then tear a piece of paper with accuracy, and you will see the difference. This paper will not focus on the results, but on the motivation behind actions. The actions discussed in this paper are big actions, taken by corporations with the ability to change society in tangible ways. The motivation behind these types of actions is shaped by common mindsets in society, and society's mindset is shaped to a considerable extent by contemporary media $[1,2]$. Contemporary media tend to focus on issues of a dramatic nature which will be a part of the decision process of big actions [3]. Design thinking has a big part to play in this arena, as design thinking makes a broader understanding of a problem available. This paper encourages broad thinking, as it states that motivation should be analysed in the two extremes, apocalyptic and utopian.

\section{BACKGROUNDS: APOCALYPTIC AND UTOPIAN MOTIVATION}

\subsection{Education}

Basic design education often focuses on form aesthetics and production, which is vital when working on consumption. Yet trends in the field of design show that designers often embark on societal issues which relate to politics and legislation more than to aesthetics. Provided that designers get a more direct role in changemaking, design education can pose a threat to positive change unless the educational institutions provide more basic teaching on societal issues.

... educators are confident that designers can create benign solutions for indigenous people, malnourishment, for example, in social, cultural, psychological and biological contexts, among others, by acquiring what is believed to represent basic skills and knowledge, such as manufacturing, design methodology, and form giving.(Gulden \& Skjøvoll, 2015) 


\subsection{Reasoning}

An action is a derivative of reasoning, and reasoning is categorized in two main ways: normative and motivating. When speaking of normative reasoning the focus is on whether a reason is good or not according to norms. The term motivating reason simply issues a reminder that the focus is on matters of motivation.

\subsection{Apocalyptic motivation}

Many scholars see apocalyptic films not only as a symptom, but also as a constitutive of existential angst. This anxiety is often a driving force in the justification of certain projects [3]. The apocalyptical narrative is strengthened not only in film, but also in the news media landscape. Evolutionary psychology tells us this is a natural phenomenon [4]. But does this also affect the minds of those creating societal change? What consequences does this yield?

Eco-anxiety is a consequence of our beneficial relationship with nature, combined with nature deteriorating, resulting in a sort of eco-grief [5]. Existential threats should incite anxiety, it is an evolutionary trait in humans that aids our survival.

The task of fixing the problem of climate change on an individual level might be too big of a task, and therefore an irrational fear that is undeserved to the individual [5]. This global threat is too big of a problem for an individual to fix and has negative mental health consequences on the individual.

\subsection{Critical utopian action research}

Critical utopian action research (CUAR) is a research method whereby researchers participate in the process of contemplating futures in a research project, typically a workshop. The group enters a space of imagination, where they form a utopian scenario in their chosen topic. Their task is then to leave this space to reify their utopia.

The Future-Creating Workshop has three phases: (1) a critique phase, where participants express their concerns about the existing system through a brainstorming session; (2) the utopia phase, in which participants express their dreams through a second brainstorming session followed by periods of group work where utopian ideas are developed by focusing specifically on dreams and wishes and putting a pause on reality; and (3) the realization phase, which is a twofold process in which the utopia groups first continue to develop the utopian ideas and then the work towards the realization of the different plans begins. [6]

CUAR is the counterpart of change motivated by avoiding apocalypse and is therefore a relevant tool to use in this context.

\subsection{System thinking}

The problem of climate change is a systemic issue, and the system of society is a contributor of climate change [7]. The societal system is driven by strong flows: political order, self-interest, the rule of law, the state [8]. The foresight landscape is equipped to consider what the system might look like in the future. System thinking will also have a part to play in the process. Effective system thinking will be a big advantage in the problem locating process [7].

\section{METHODS: CASE STUDY}

This paper analyses two cases of action and their motivation, based on the language used in their justifications. The purpose of this is to laterally understand two different actions and compare them. The cases include different sustainability-driven actions taken by Equinor, the United Nations, and nongovernmental organizations. The information saturating this paper was collected through analyses of documents and websites.

\section{RESULTS}

\subsection{Case study 1: Carbon capture and storage}

'[Carbon capture and storage] CCS is one of the measures that the UN Intergovernmental Panel on Climate Change recommends keeping global warming to 1.5 degrees Celsius. The International Energy Agency states that we will need to store billions of tonnes of $\mathrm{CO}_{2}$ every year if we are to reduce global warming.' [9] 
This is Equinor's justification to why they want to implement carbon capture as part of their portfolio. They justify their decision by saying that the International Energy Agency encourages carbon storage in order to reduce global warming. The language hints towards an apocalyptic motivation. Equinor is capturing carbon so that a situation which will lead to the consequences of climate change does not happen. This action is happening due to apocalyptic fear. Fear of internal economic decline may also be an incentive for an action such as this.

The company might face sanctions or consequences for its reputation if it does not confine itself to the Paris Agreement restrictions. Equinor is a company that deals with the substance that is contributing the most to greenhouse gas emissions, which is an activity that is regulated by the Paris Agreement [10].

The motivation for CCS lies on different levels, but when observing Equinor's wording, it looks like they are doing this for sustainable development. But we can also observe the government and the United Nations very directly affecting the possible behaviour which corporations such as Equinor can engage in with regard to sustainability. One of the UN's main priorities is to improve people's well-being [10]. The UN has imposed CCS on Equinor through the Paris Agreement, which was organized to improve people's well-being. In this sense, the motivation behind carbon storage is utopian from the UN's perspective. On the contrary, the language used by Equinor signifies apocalyptic motivation. The different mindsets here can contribute to an unclear goal. Literature on project leadership says that all parts of a project need to see the goal and their own motivation with the same eyes [11].

\subsection{Case study 2: The climate lawsuit}

Non-governmental organisations have decided to sue the government of Norway because they think the government is undermining the constitution by giving permission to extract oil from the lithosphere [13].

The climate lawsuit is another example of a solution grounded in apocalyptic motivation. The NGOs are concerned that the government's decision to grant oil drilling licenses will hinder the UN's goal of not exceeding a global average temperature of 1.5 degrees Celsius. Again, the motivation is to stop development that might lead to an apocalyptic world.

The case of the climate lawsuit is similar to the case of CCS, which is an action taken to reduce the level of greenhouse gas emissions. While the climate lawsuit has the same goal, the motivation is causally related to the existential threat of the oil industry and its emissions.

The climate lawsuit is an agent, in this case multiple NGOs and a legal team, trying to hinder another agent in its negative contribution to the greenhouse gas economy. This action is clearly motivated by the fear of an apocalyptic future.

The justification for the lawsuit is that the government is undermining Norway's constitution by handing out licenses to extract oil in the Arctic Ocean. The specific article they are referring to is Article 112 if the Norwegian constitution, which states that everybody has the right to a liveable climate. The agent suing the government states that the amount of oil discovered, if used, is greater than society can consume if we want to uphold the Paris Agreement's goal of not exceeding a global average temperature of 1.5 degrees. The constitution is not upheld because handing out superfluous licenses contradicts Article 112 by contributing to exceeding a global average temperature of 1.5 degrees.

The action of filing a lawsuit against the Norwegian government seems to be grounded in a fear of an apocalyptic future. The action is made possible by the intention of the constitution's Article 112, the wording of which seems to be founded on a utopian motivation. The Article reads as follows:

Every person has the right to an environment that is conducive to health and to a natural environment whose productivity and diversity are maintained. Natural resources shall be managed based on comprehensive long-term considerations which will safeguard this right for future generations as well. To safeguard their right in accordance with the foregoing paragraph, citizens are entitled to information on the state of the natural environment and on the effects of any encroachment on nature that is planned or carried out.

The authorities of the state shall take measures for the implementation of these principles. [2]

The constitution's Article 112 states very clearly in its first paragraph that it exists to ensure the right of maintaining a natural, productive and diverse environment. The agent suing the government has apocalyptic motivation for the lawsuit. This suggests that the agent has a certain misunderstanding of what the constitution is intended for. The agent is pursuing an anti-apocalyptical goal which is rooted in apocalyptical motivation, but part of their reasoning is an action with utopian intentions. 


\section{DISCUSSIONS OF THE FINDINGS}

This project has examined the presence of apocalyptic or utopian motivation in different environmental actions. The aim of the paper is to enhance the understanding of justifications regarding action with consequences to society.

The paper strengthens the hypothesis that justifying a project with utopian motivation might yield positive outcomes, but there is no guarantee for this. Such is also the case for apocalyptically inspired cases. Being mindful of these concepts can steer projects in more prosperous directions. When deciding what projects are important or whether a company should go through with it, the results in themselves might be good motivation, but the effect of the project can be defined before the project starts. If a project aims to better the world, the underlying motivation may steer the project towards failure [3].

\section{CONCLUSIONS}

I have tried to understand motivation as a duality, on either end of the spectrum of positive and negative, both anchor points of change which can yield results both good and bad. The mindfulness and clarity of the base motivation of any change is something I advise considering when in the planning phase of any project. Starting a project by defining motivation might cause the execution of the project to grow into something infinitely different than a project where motivation was not considered. What would Equinor's reaction to the Paris Agreement be if they too sought to improve the well-being of people? CCS is an action that is meant to secure well-being, it is not meant to improve wellbeing, as the Paris Agreement is.

The findings of this paper suggest that designers and changemakers can benefit from thinking in both an apocalyptic and a utopian manner when deciding the goal of a project. The project's goal can be put into the extreme scenarios. Does the project aim to better the world, or to protect it? Both are possible motivations for the same project. but choosing a direction can be beneficial to the participants of a project. We want to protect children in a kindergarten, so we build a fence around it. We do not want to worry about children, so we build a fence around this kindergarten. The difference in motivation may affect the result aesthetically, ethically, practically, and in many other ways. The UN tackles the problem of sustainable development by wanting to make positive change and securing well-being, and Equinor has the same problem, but they want to store carbon so that the temperature does not rise. Comparing problems, solutions and motivation is not easy, not always in good faith, but it can contribute to better solutions when making change. Differentiating between 'bettering the world' and 'not worsening the world' can be a key turning point in any project.

An action which is made possible and carried out by different agents, where one or some agents have apocalyptic reasons for inciting that action, and the other(s) have utopian reasons for carrying out that action, might benefit our environment in similar respects, but the outcome the different parties seek might not end up as intended.

\section{REFERENCES}

[1] Bandes S. A. Fear Factor: The Role of Media in Covering and Shaping the Death Penalty. Ohio State Journal of Criminal Law. 2004; Vol. 1: p. 585, 2004.

[2] The Constitution of the Kingdom of Norway. 2020 [Available: https://lovdata.no/dokument/NLE/lov/1814-05-17.

[3] Gulden T. and Skjøvoll V. (2015). RULES AND COMPLEX THINKING IN DESIGN EDUCATION. In International Conference on Engineering and product Design, E\&PDE'15

[4] Harper E. T. Ecological Gentrification in Response to Apocalyptic Narratives of Climate Change: The Production of an Immuno-political Fantasy. International Journal of Urban and Regional Research. 2020; 44:55-71.

[5] Marano H. E. Our Brain's Negative Bias. Psychology Today, 2003 [updated 2019. Available: https://www.psychologytoday.com/us/articles/200306/our-brains-negative-bias.

[6] Usher K., Durkin J., and Bhullar N. Eco-anxiety: How thinking about climate change-related environmental decline is affecting our mental health. International Journal of Mental Health Nursing. 2019; 28:1233-4.

[7] Tofteng D. and Husted, M. Critical utopian action research. The SAGE Encyclopaedia of Action Research. 2014:231-2.

[8] Meadows D. Dana (Donella) Meadows Lecture: Sustainable Systems. Jennifer Lynn; 2013.

[9] Fukuyama F. The Origins of Political Order. Farrar, Straus and Giroux; 2011. 
[10] Equinor. Carbon capture, utilization and storage. Available: https://www.equinor.com/en/whatwe-do/carbon-capture-and-storage.html.

[11] United Nations. Promote sustainable development. Available: https://www.un.org/en/sections/what-we-do/promote-sustainable-development/index.html.

[12] Aakre J. and Scharning H. S. Prosjekthåndboka 3.0 - verktøykasse for kreative team. Universitetsforlaget; 2016.

[13] Okonkwo T. How International Law Can Deal with Lack of Sanctions and Binding Targets in the Paris Agreement. Journal of Sustainable Development. 2017 Vol. 10 (no. 5).

[14] Klimasøksmål. Derfor saksøker vi. Available: https://www.xn--klimasksml-95a8t.no/omsaken/derfor-saksoker-vi-staten/. 